\title{
Characterization of Electromagnetic Properties of In Situ Soils for the Design of Landmine Detection Sensors: Application in Donbass, Ukraine
}

\author{
Timothy Bechtel ${ }^{1, *}$, Stanislav Truskavetsky ${ }^{2}$, Gennadiy Pochanin ${ }^{3}$, Lorenzo Capineri ${ }^{4}$, \\ Alexander Sherstyuk ${ }^{2}$, Konstantin Viatkin ${ }^{2}$, Tatyana Byndych ${ }^{2}$, Vadym Ruban ${ }^{3}$, \\ Liudmyla Varyanitza-Roschupkina ${ }^{3}$, Oleksander Orlenko ${ }^{3}$, Pavlo Kholod ${ }^{3}$, Pierluigi Falorni ${ }^{4}$, \\ Andrea Bulletti ${ }^{4}\left(\mathbb{D}\right.$, Luca Bossi ${ }^{4}\left(\mathbb{C}\right.$ and Fronefield Crawford ${ }^{1}(\mathbb{1})$ \\ 1 Franklin \& Marshall College, Lancaster, PA 17603, USA; fcrawfor@fandm.edu \\ 2 National Scientific Center, Institute for Soil Science and Agrochemistry Research named after O.N. \\ Sokolovsky, 61024 Kharkiv, Ukraine; starwalkerone@gmail.com (S.T.); sherstyukalex@gmail.com (A.S.); \\ konstan.akari@gmail.com (K.V.); tanyabyndych@mail.ru (T.B.) \\ 3 O.Ya. Usikov Institute for Radiophysics and Electronics National Academy of Sciences of Ukraine, \\ 61085 Kharkiv, Ukraine; gpp@ire.kharkov.ua (G.P.); ruban@ire.kharkov.ua (V.R.); \\ lvr@ire.kharkov.ua (L.V.-R.); oao@ire.kharkov.ua (O.O.); kholod@ire.kharkov.ua (P.K.) \\ 4 Dipartimento Ingegneria dell'Informazione, Università degli Studi di Firenze, 50139 Firenze, Italy; \\ Lorenzo.capineri@unifi.it (L.C.); pfalorni@gmail.com (P.F.); andrea.bulletti@unifi.it (A.B.); \\ 1.bossi@unifi.it (L.B.) \\ * Correspondence: tbechtel@fandm.edu; Tel.: +1-717-468-8556
}

Received: 30 April 2019; Accepted: 21 May 2019; Published: 24 May 2019

\begin{abstract}
To design holographic and impulse ground penetrating radar (GPR) sensors suitable for humanitarian de-mining in the Donbass (Ukraine) conflict zone, we measured critical electromagnetic parameters of typical local soils using simple methods that could be adapted to any geologic setting. Measurements were recorded along six profiles, each crossing at least two mapped soil types. The parameters selected to evaluate GPR and metal detector sensor performance were magnetic permeability, electrical conductivity, and dielectric permittivity. Magnetic permeability measurements indicated that local soils would be conducive to metal detector performance. Electrical conductivity measurements indicated that local soils would be medium to high loss materials for GPR. Calculation of the expected attenuation as a function of signal frequency suggested that $1 \mathrm{GHz}$ may have optimized the trade-off between resolution and penetration and matched the impulse GPR system power budget. Dielectric permittivity was measured using both time domain reflectometry and impulse GPR. For the latter, a calibration procedure based on an in-situ measurement of reflection coefficient was proposed and the data were analyzed to show that soil conditions were suitable for the reliable use of impulse GPR. A distinct difference between the results of these two suggested a dry (low dielectric) soil surface, grading downward into more moist (higher dielectric) soils. This gradation may provide a matching layer to reduce ground surface reflections that often obscure shallow subsurface targets. In addition, the relatively high dielectric deeper $(10 \mathrm{~cm}-20 \mathrm{~cm})$ subsurface soils should provide a strong contrast with plastic-cased mines.
\end{abstract}

Keywords: chernozem; ground penetrating radar; holographic radar; landmine; metal detector; soil permittivity; soil conductivity; soil magnetic permeability; attenuation; water content 


\section{Introduction}

In active and former conflict zones across the globe, there are daily landmine casualties. The majority $(79 \%)$ are civilians and almost half $(46 \%)$ are children [1]. The 1998 Ottawa Mine Ban Convention, nearly halted production of anti-personnel mines, and drastically reduced deployment. In recent years, a myriad of mined or suspect areas have been released for productive use, and for a time, there has been a steep decline in casualties. However, well over 10 million stockpiled mines await destruction [1], and several major powers have not joined the Ottawa treaty.

Since April 2014, separatists have controlled much of the Ukrainian Oblasts of Donetsk and Luhansk ("Donbass") in an area formerly designated by the government as the Anti-Terrorist Operations (ATO) Zone, recently re-named the Joint Forces Operations (JFO) Zone (Figure 1). Inside and near the ATO Zone, landmines have killed over 3000 persons [2]. In preparation of post-conflict humanitarian demining, we have developed a low-cost, multi-sensor, robotic scanning device based on a commercial off-the-shelf (COTS) vehicle modified to autonomously operate multiple sensors.
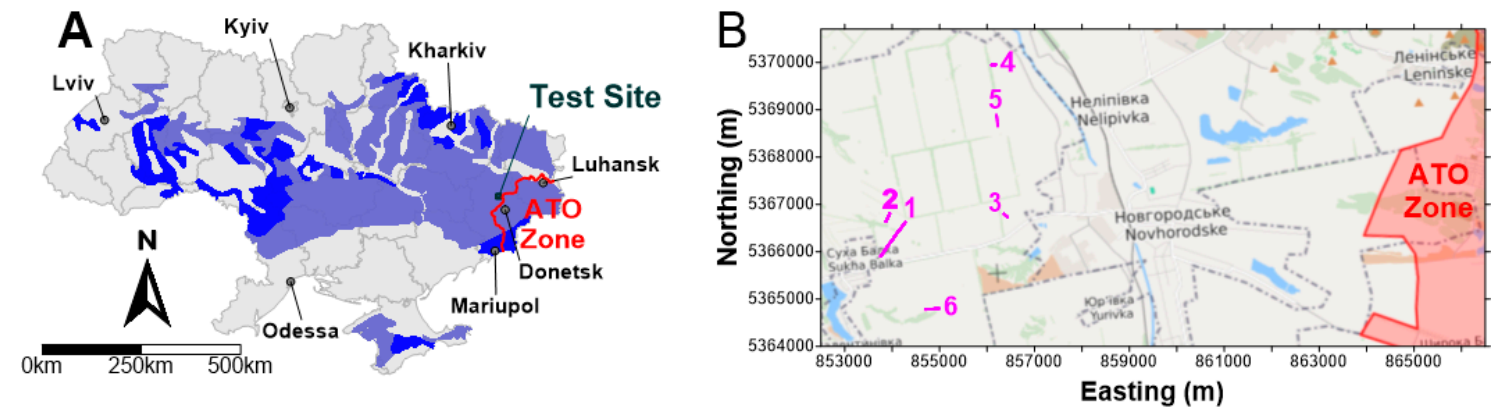

Figure 1. (A) Chernozems soils of Ukraine and study site. (B) Survey transects and Anti-Terrorist Operations Zone (ATO) zone.

Among the techniques proposed for humanitarian demining [3], we chose holographic subsurface radar [4] and impulse ground penetrating radar (GPR) [5], to be eventually supplemented by a metal detector, sensorized prodder [6], and a 3-D time-of-flight camera. The advantages of this combination of sensors was that they could be operated remotely and could provide real-time data. The impulse GPR provides fast detection and precise localization of shallow mine-like targets, while the slower-scanning holographic radar provides high-resolution imaging of targets to allow the discrimination of dangerous mines from harmless, but ubiquitous, clutter [7]. The prodder can provide further discrimination by identifying non-compliant objects that might have a mine-like shape (e.g., a rounded rock). The 3-D camera provides information on the working environment such as potential obstacles and trip wires, and detection of recently-disturbed soils, and correction of holographic images for surface roughness.

In developing this system, we were mindful of the critical factors emphasized by "Jane's Mines and Mine Clearance" editor C. King who said that "To develop realistic techniques and procedures that will truly enhance the process of mine clearance, two primary factors must be considered: Mines \{the variety and the ways they are used\}, and the environment \{limitations imposed by real minefield conditions\} ... with equipment and techniques closely tailored to the specific threat \{and conditions\} in each minefield" [8].

To that end, the types of anti-tank (AT) and anti-personnel (AP) landmines reportedly used in the ATO zone (Table 1), and the general local soil characteristics were reviewed in our previous work [9]. Comparison of these characteristics with our work on impulse and holographic GPR $[4,10]$ suggested a signal operating frequency (OF) for continuous wave holographic radar, and a center operating frequency (COF) for ultrawideband (UWB) impulse radar of around $2 \mathrm{GHz}$.

For the success of the holographic and impulse GPR, and metal detector (MD) methods, the electromagnetic properties of soils is critical. Extremely high conductivity of soils can produce false alarms with a MD, and unacceptable attenuation of electromagnetic waves for GPR. Dielectric 
permittivity of the soil is important since a strong contrast between soil and mines makes detection possible [10-13]. For successful humanitarian demining, it is necessary to understand the range and lateral variability in electromagnetic properties of the local soils [14]. General data on local soils are often available in many parts of the world, but for demining, specific and detailed data are required for detection system design, and during data processing for field operations.

Table 1. Expected mines in Donbass.

\begin{tabular}{cccccc}
\hline Type $^{*}$ & Use & Diameter $(\mathbf{m m})$ & Length $\mathbf{( m m})$ & Casing & Metal Parts \\
\hline PMN-2 & AP & 121 & Plastic & Yes \\
\hline PMN-4 & AP & 95 & 337 & Plastic & Yes \\
PTM-1G & AT & 69 & & Metal & Yes \\
TM-62M & AT & 320 & Plastic & Yes \\
TMM62-P3 & AT & 320 & &
\end{tabular}

* Above-ground "stake mines" such as MON-50 were not considered.

This study represented the first electromagnetic characterization of native, in situ Donbass soils. GPR has been investigated in Donbass for use in railway bed inspection [15] and for landmine detection [16], but the medium for both studies was not native soil, so they provided no information on the electromagnetic properties of local soils and their variation. While there was some data in the literature regarding electromagnetic properties of soils in the Western Polesie region of Northwest Ukraine [17], there was no specific data on electromagnetic properties of native Donbass soils. Therefore, to ensure that the signal characteristics of our proposed sensors were suitable for this region, we completed electrical and electromagnetic measurements on fields, containing typical soils. These experiments were conducted at an experimental station of the Institute for Soil Science and Agrochemistry Research named after O.N. Sokolovsky in Sukha Balka, approximately $7 \mathrm{~km}$ to $10 \mathrm{~km}$ west of the ATO (Figure 1). These first-ever data on the specific electromagnetic characteristics (and range of variation) of in situ Donbass soils also made it possible to construct laboratory test beds that simulated actual conditions, as opposed to a simple (and unrealistic) "sand boxes." The approach described herein was simple, and could be widely applied to ensure landmine detection GPR and MD sensors are designed appropriately for any geologic setting.

\section{Soils in Donbass}

Based on existing generalized soils mapping [18] by the UN Food and Agriculture Organization (FAO) and detailed mapping by the Soil Science Institute (Figure 2), over 70\% of the soils in Donbass are haplic (typical) chernozems, approximately 10\% are varieties of luvic (clay-enriched) chernozems, and the remainder are non-chernozem soils (earth tone shades in Figure 2) developed in alluvial or colluvial sediments. All chernozems (shades of blue in Figure 2) are organic-rich soils that develop on relatively flat surfaces under thick grass vegetation of the Steppe Zone in climates with cold winters and hot summers [19-21]. Because AP mines are typically buried at less than $10 \mathrm{~cm}$ (as opposed to up to $30 \mathrm{~cm}$ for AT) [22], the surficial layer (plow zone in cultivated areas) of these chernozemic soils would be the most relevant for evaluating GPR and MD. Especially in an active or former combat zone, we did not expect soils to be clean and homogeneous. Instead there were likely to be bits of shrapnel, shell casings or other debris, and variations in clay or moisture content. Thus, our intent was not to characterize clean soil, but to understand the soil/water/junk/rocks mixture that de-mining operations would encounter. 


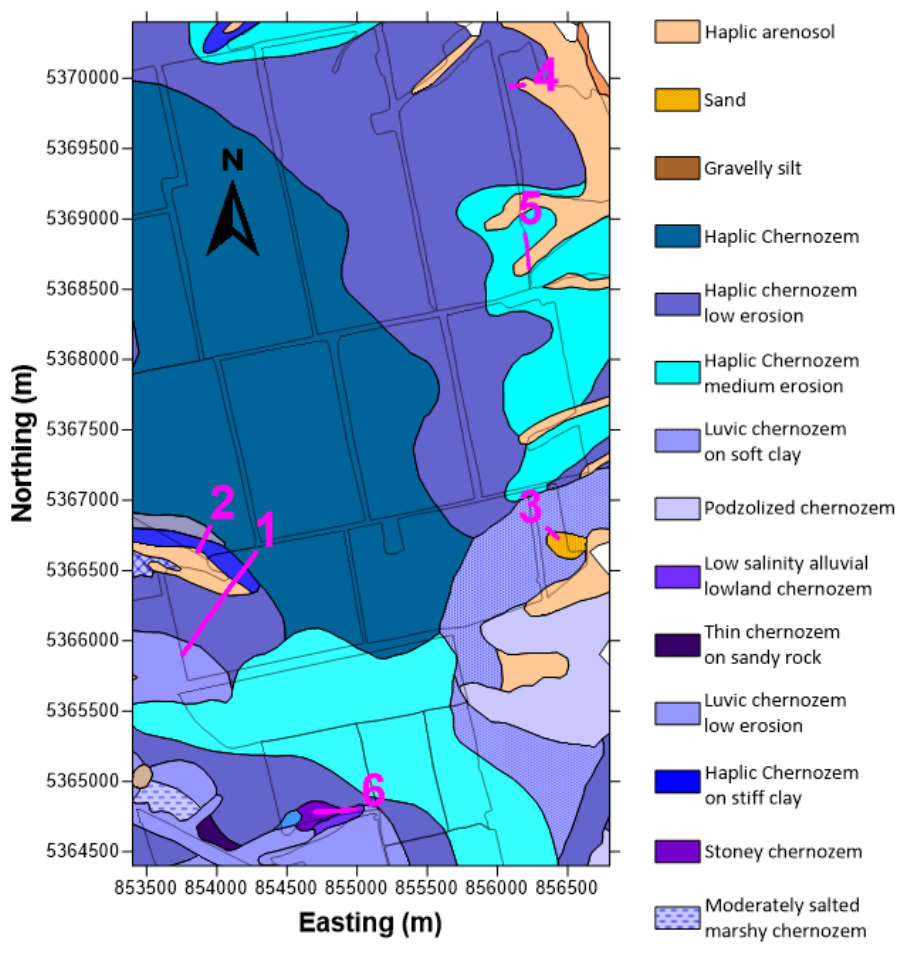

Figure 2. Transect locations and soil map of the study area.

\section{Field Methods}

The most important soil properties influencing MD performance are magnetic susceptibility (or permeability) and electrical conductivity [23]. Soil moisture content also plays a secondary role since it can influence the conductivity, particularly in clay-rich soils.

For GPR, the important parameters are electrical conductivity as well as dielectric permittivity $[24,25]$. Magnetic permeabilities within the normal ranges for most soils have no effect on GPR [24]. To characterize actual Donbass soils, we chose to make field measurements of magnetic permeability $(\mu)$, electrical conductivity $(\sigma)$, and dielectric permittivity $(\varepsilon)$. These parameters are all frequency-dependent [25], so the OF or COF of field instruments was important and is accounted for in later sections. The instruments employed, and their specifications are listed in Table 2, and is depicted in Figure 3. These represent the state-of-the-art for field measurement of the respective parameters [26-28], with the last entry representing a custom-built, innovative, purpose-built antenna system and procedure for measuring the ground surface reflection coefficient (and therefore the surficial dielectric permittivity) as described below.

Table 2. Measuring equipment.

\begin{tabular}{ccccc}
\hline Parameter & Manufacturer & Model & OF & Deployment Details \\
$\begin{array}{c}\text { Magnetic } \\
\text { permeability } \mu\end{array}$ & Bartington & MS2 & $\frac{580 \mathrm{~Hz}}{2}$ & MS2F probe fully inserted into soil \\
\hline $\begin{array}{c}\text { Electrical } \\
\text { conductivity } \sigma\end{array}$ & $\begin{array}{c}\text { L and } \mathrm{R} \\
\text { Instruments }\end{array}$ & MiniRes & $\frac{-}{\text { DC }}$ & Wenner array; 10-cm electrode spacing \\
\hline $\begin{array}{c}\text { Dielectric } \\
\text { permittivity } \varepsilon_{\mathrm{TDR}}\end{array}$ & $\begin{array}{c}\text { Spectrum } \\
\text { Technologies }\end{array}$ & Field Scout 300 & $\frac{-}{2100 \mathrm{MHz}}$ & 7.5 cm probes \\
\hline $\begin{array}{c}\text { Dielectric } \\
\text { permittivity } \varepsilon_{\mathrm{R}}\end{array}$ & Custom & - & $\frac{-}{1.2 \mathrm{GHz}}$ & $\begin{array}{c}\text { 1-transmitter, 2-receiver impulse GPR; paired } \\
\text { measurements over aluminum sheet and ground }\end{array}$ \\
\hline
\end{tabular}



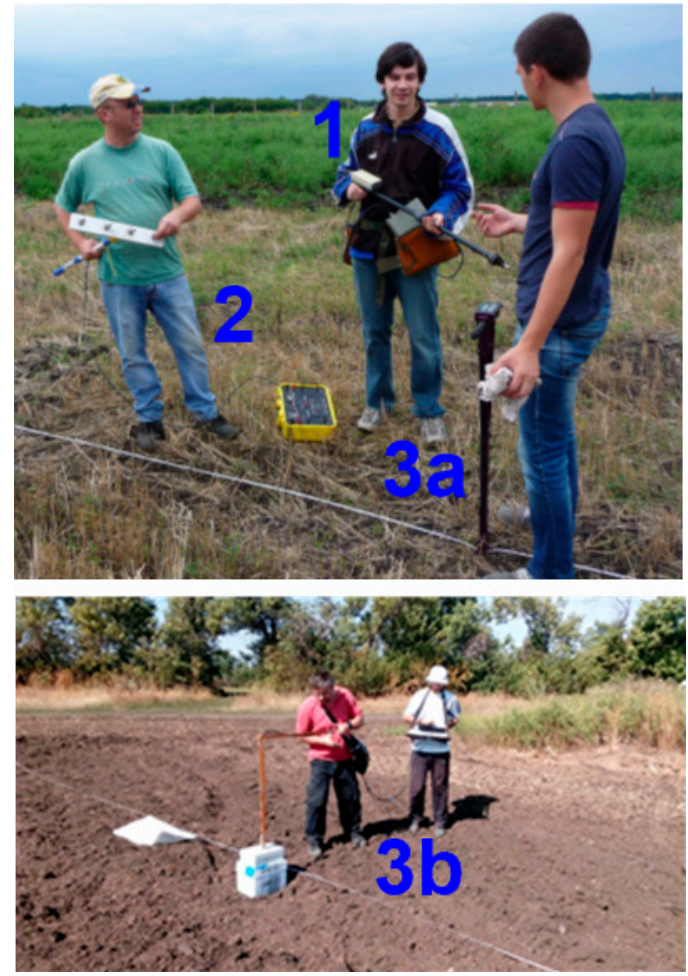

Figure 3. Photographs of field equipment. (1) Bartington MS2 magnetic susceptibility meter with MS2F probe, (2) L\&R Instruments MiniRes with 4-electrode probe. (3a) Spectrum Technologies Field Scout 300 TDR. (3b) Purpose-built 1-Tx, 2-Rx impulse GPR.

Magnetic permeability was measured by inserting a Bartington MS2F probe fully into the soil and reading the magnetic susceptibility, (which was easily converted to permeability) with an MS2 meter. For electrical conductivity, an L\&R Instruments MiniRes earth resistivity meter was connected to a custom-built four-probe Wenner array style "pitchfork" probe with 10-cm A-spacing (for an effective measurement depth of approximately $10 \mathrm{~cm}$ ).

For subsurface dielectric permittivity, a Spectrum Technologies, Inc. Field Scout 300 time-domain reflectometry (TDR) instrument was used to read raw GPR pulse travel times (in units of nanoseconds) along the two $7.5-\mathrm{cm}$ steel spike waveguides (probes) rather than the calibrated volumetric water content, which is typically recorded. For this survey, the raw wave guide travel times were recorded, and converted to a TDR-derived dielectric permittivity $\left(\varepsilon_{\mathrm{TDR}}\right)$ based on empirical laboratory calibration of the waveguide travel times (see Figure 4) using various materials with known relative dielectric permittivity at $20^{\circ} \mathrm{C}[29]$.

Expected errors in field measurement of these parameters will not have been dominated by the benchtop or field precision of the instruments. Instead, we anticipated that the largest variations would be due to the (unknown) presence of inhomogeneities in mineralogy, grain size, moisture content and war- and/or agriculture-related clutter.

The TDR permittivity $\left(\varepsilon_{\mathrm{TDR}}\right)$ was measured with a relatively low-frequency ( $\left.100 \mathrm{MHz} \mathrm{COF}\right)$ instrument. To make measurements at a frequency closer to the design COF of $2 \mathrm{GHz}$, and to address the partitioning of the transmitted radar signal at the ground surface for the air-coupled impulse GPR, another estimate of permittivity was desired. There are several GPR-based methods for measuring soil permittivity [30]: Recording of signals scattered by small conductive objects in the subsurface [31,32], common midpoint and common-offset reflection methods [33], and the groundwave technique [14,34]. A new method for location of subsurface objects and simultaneous estimation of electromagnetic wave velocity in the ground (which is as important for mine location than permittivity alone) based on analyses of times-of-flight for signals from an impulse GPR transmitter (Tx) to a subsurface reflector 
and back to four receiver $(\mathrm{Rx})$ antennas distributed about the transmitter was proposed in [35]. The innovation in this method was the possibility to determine the wave velocity simultaneously with calculation of the subsurface object's position.

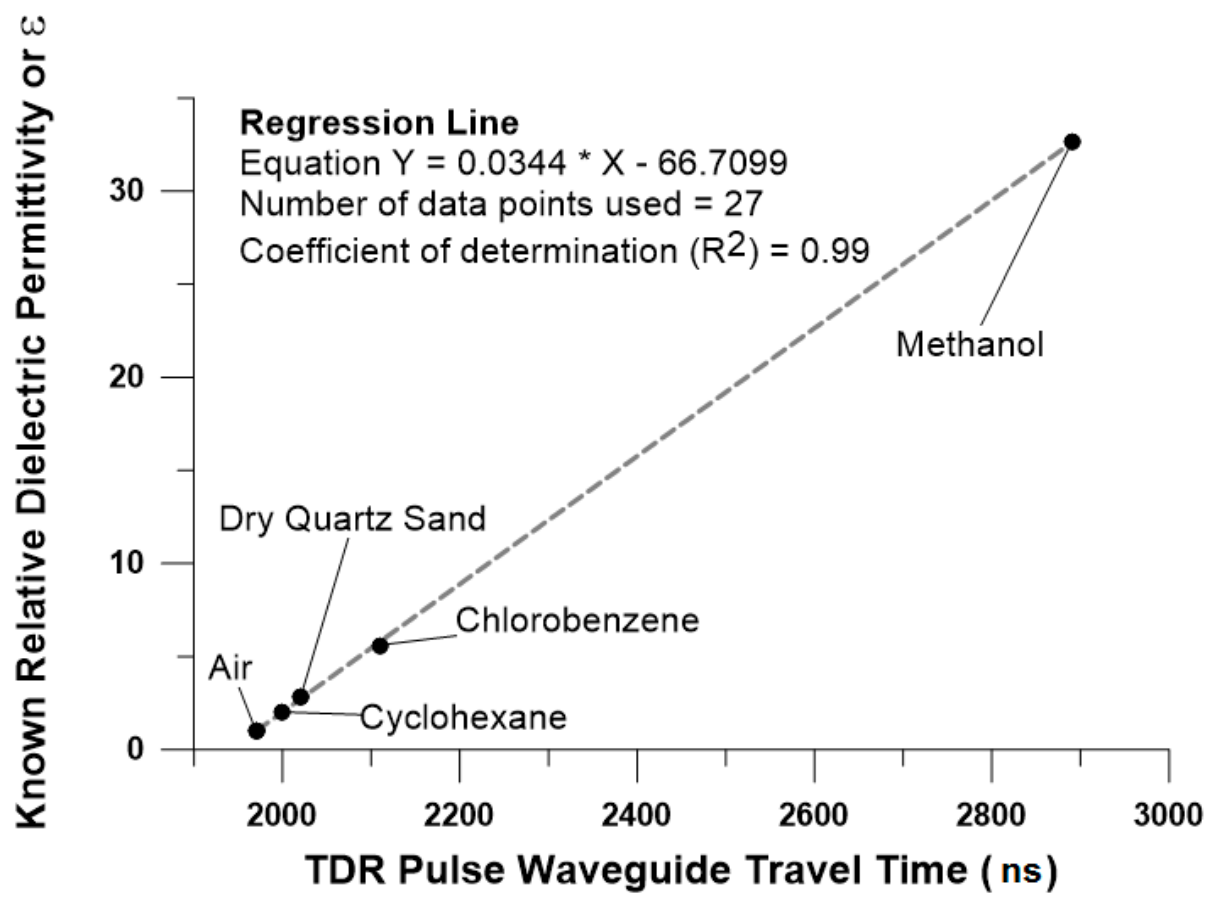

Figure 4. Calibration curve for conversion of TDR pulse transit times to dielectric permittivity.

Nearly all the GPR-based methods mentioned above require reflection from a subsurface target, and this limits their general application as means for permittivity measurements in unknown, and potentially target-free, soil conditions. More complicated methods based on solution of inverse scattering problems have been suggested using a microwave tomography approach [36], or a global multi-level coordinate search algorithm for reconstruction of the vertical profile of permittivity and conductivity for a layered soil [37]. The inverse scattering provides quite accurate soil electromagnetic properties, but collection of reflection coefficients at thousands of frequencies at each field measurement station, and inversion to obtain the parameters, consumes considerable time and computer resources, and the equipment for utilizing these methods is not widely available. We desired a rapid affordable method for characterizing bulk earth properties in or near an actual war zone; the properties that will be encountered in demining operations. In this study, we complemented the subsurface TDR data by measuring the reflection coefficient (permittivity) of the soil surface. In this method (adapted from [5]), it was enough to measure two UWB impulse reflected waves: The reflection from a metal sheet lying on the soil surface (for calibration) and the reflection from the soil surface itself. During both recordings, the GPR antenna system had to be maintained at a constant height. The waveform reflected by the metal sheet could be recorded once per day and used to compare all subsequent soundings. This simple method used for the estimation of surficial permittivity is described in detail below. It is important to note that we did not consider attenuation (loss) from propagation within the soil in this method. A discussion about the use of impulse GPR for layered medium characterization is provided below.

The dielectric permittivity $\left(\varepsilon_{R}\right)$ based on the reflection coefficient $(R)$ for a $1.2 \mathrm{GHz}$ GPR pulse is given as:

$$
\varepsilon_{R}=\left(\frac{1-R}{1+R}\right)^{2}
$$


In this equation, $\mathrm{R}$ is the ratio of the amplitude of the reflected wave to the amplitude of the incident wave. For completeness, it is necessary to consider the case when the thickness $\mathrm{d}$ of the soil layer(s) was less than the velocity $v$ in a dielectric(s) multiplied by $\tau$, the duration of the impulse. Since we used the maximum of the amplitude of the reflected wave in the calculation, we had to wait until the maximum of the field strength of the incident impulse wave crossed the upper boundary, at which time the maximum amplitude of the reflected wave started propagating back to the observation point. This term corresponded to the rise time of the impulse. If the rise time was 0.4 ns and $\varepsilon_{R} \approx 4$, then this GPR method allowed us to estimate the permittivity of a mixture of soils at a depth of less than approximately $6 \mathrm{~cm}$. Unfortunately, this method in its simplest variant did not give us any information about the distribution of permittivities inside the $6-\mathrm{cm}$ interval. However, even this information could be used to predict the radar contrast of a plastic mine in the soil and to adjust (optimize) the sounding parameters appropriately.

The reflected wave amplitude was measured by a 1-Tx, 2-Rx GPR system at a known height $(\mathrm{h}=37 \mathrm{~cm})$ above the ground as depicted in Figure 5 . Note that this was an average height over the illuminated footprint (approximately $70 \times 70 \mathrm{~cm}^{2}$ ) since the soil surface is naturally rough. To get the amplitude of the incident wave, we placed a metal sheet on the ground surface and recorded the totally-reflected signal. In this case, the reflection coefficient equaled "- 1 ". Therefore, the signal reflected by the metallic sheet allowed us to derive the amplitude of the incident wave.

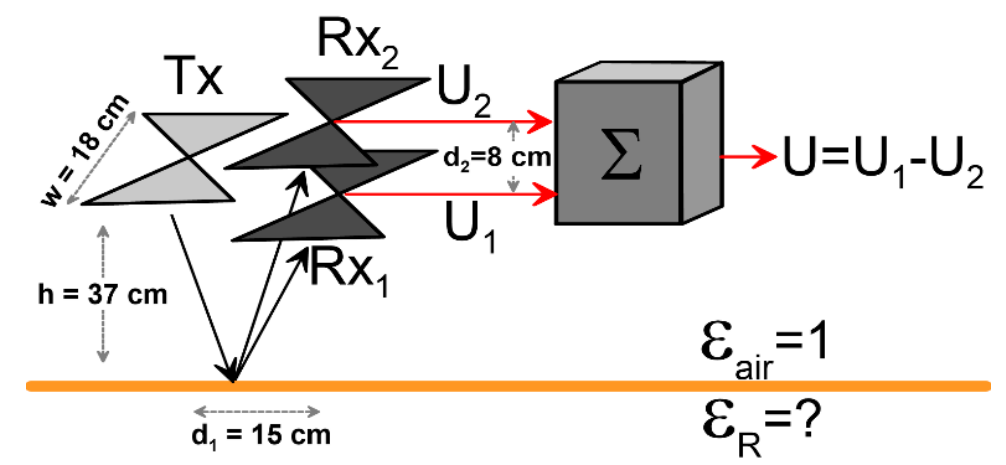

Figure 5. Schematic of 1-Tx, 2-Rx impulse GPR for simple measurement of surface reflection coefficient, with Rx differencing to suppress direct coupling signal.

Equation (1) is correct for the case when a plane wave is incident perpendicular to the air-ground interface. We used a bistatic antenna system with separated Tx and Rx antennas. To provide conditions as close as possible to normal incidence, we deployed Tx and Rx antennas with minimum possible offset distance $(\mathrm{d} 1=15 \mathrm{~cm})$. This produced coupling between $\mathrm{Tx}$ and $\mathrm{Rx}$, with a large direct signal through which we had to detect and record the actual reflection from the ground surface. To overcome this, we used a patented differential Rx module [38], which eliminated the direct coupling interference. As depicted in Figure 5, the Tx dipole illuminated the ground surface. The receiving module, with dipole pair Rx1 and Rx2 at small vertical separation $(\mathrm{d} 2=8 \mathrm{~cm})$ outputed the differential voltage (U) which represented only the reflected signal. Detailed descriptions of this antenna system and previous testing (including the minimal effects due to deviation from a true plane wave) can be found in [10,39], and the calibration procedure is described in the Appendix A.

To collect data for calculation of the reflection coefficient $\mathrm{R}$, we recorded reflections from the ground surface at a fixed height (see sensor $3 b$ in Figure 3). This was repeated with the metal sheet covering the ground surface beneath the GPR. At each measurement station, we recorded reflected waveforms from the ground surface and from the metal sheet. Examples of these signals are shown in Figure 6. The small differences in the peak arrival time for the metal sheet versus ground were due to a combination of factors including variations in reflected arrival time from different points on a rough surface, and differing penetration depth into the ground for the transmitted signal. Moreover, if the soil surface was not flat, we could not tightly align the metallic sheet to the soil 
surface. Therefore, the reflection from the metal propagated a smaller distance and arrived at the receiver slightly earlier than the reflection from the soil. Since the amplitude of the electromagnetic field decreased approximately as $1 / \mathrm{r}$ (inverse of range), the slight difference in $\mathrm{r}$ for measurements of the reflection coefficients from soil and metal could influence measurements of the signal amplitude and, consequently, the resulting permittivity of the soil. We noted this as a possible source of error.

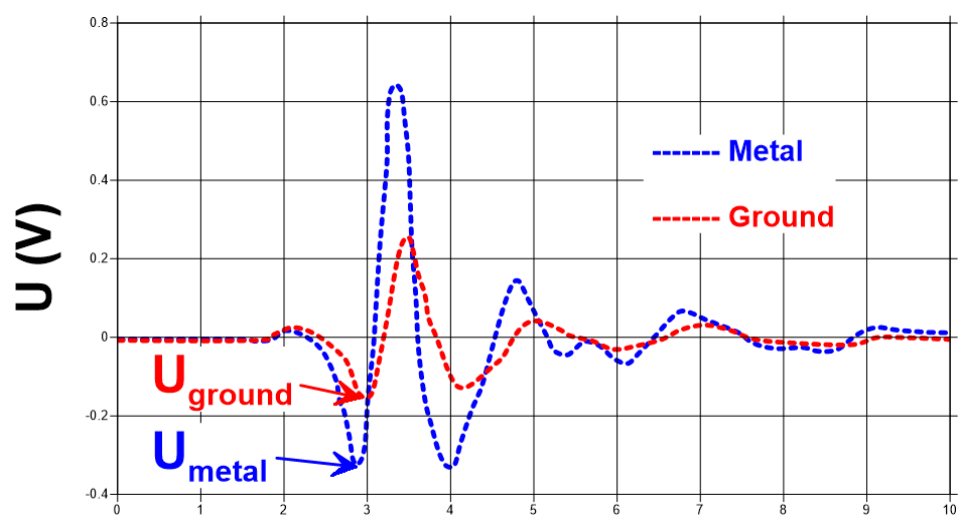

Time (ns)

Figure 6. Example waveforms from the GPR system in Figures $3 b$ and 5.

The reflection coefficient $\mathrm{R}$ was then given by:

$$
R=\frac{-U_{\text {ground }}}{U_{\text {metal }}}
$$

where $\mathrm{U}$ are voltages as marked in Figure 6. The negative sign was necessitated by the polarity reversal of the transmit pulse upon reflection by the metal sheet.

For all methods, measurements were recorded at 2-meter intervals along six transects, totaling $1845 \mathrm{~m}$ of profile (for a total of nearly 1000 field readings for each parameter). Readings were recorded digitally in instrument memory, and in a bound field book for backup and quality control. Station locations were recorded using differential GPS with sub-meter accuracy. The field effort spanned four days during which the weather was consistently warm and sunny, with no precipitation (and none in the preceding days).

\section{Measurement Results}

The measured and/or derived soil electromagnetic parameters recorded along the six survey transects are plotted in Figure 7. The profiles also showed the lateral contacts between soil types. All the profiles showed considerable short-scale variation in individual parameters, but the physically-independent parameters seemed to generally track each other over longer scales. We tentatively interpreted this as linkage between parameters due to, e.g., the simultaneous effects of moisture content on dielectric and conductivity, and the possible coincident effect of clay content on conductivity and magnetic permeability. Note that conductivity data were not collected along transect 5 , due to a very stony surface.

Values for soil electrical conductivity $(\sigma)$ range between 25 and $65 \mathrm{mS} / \mathrm{m}$. Based on a rough (but common) rule-of-thumb [40] for GPR skin depth ( $\mathrm{z}=35 / \sigma$ for $\sigma$ in $\mathrm{mS} / \mathrm{m}$ and $\mathrm{z}$ in $\mathrm{m}$ ), these values suggest an effective GPR survey depth in Donbass of between $1.4 \mathrm{~m}$ and $0.5 \mathrm{~m}$. This rough rule does not, of course, consider signal frequency as discussed below.

On Figure 7, the vertical scales for the plots of $\varepsilon_{\mathrm{TDR}}$ and $\varepsilon_{\mathrm{R}}$ were different due to an order of magnitude difference between the two. Although some difference was surely due to the different frequencies for the measuring systems (TDR vs. GPR), we interpreted this order of magnitude difference 
as being largely due to a very dry soil surface (yielding $\varepsilon_{R}$ based on surface R), grading downward into more moist soils (characterized by $\varepsilon_{\mathrm{TDR}}$ as measured by TDR). This difference in dielectric is highlighted in Figure 8, which shows the median $\varepsilon$ for each method for each soil type. The smallest variation in values for $\varepsilon_{R}$ was seen for the sand soil. This may be explained by a generally smoother soil surface with less scattering loss for the reflected GPR pulse.
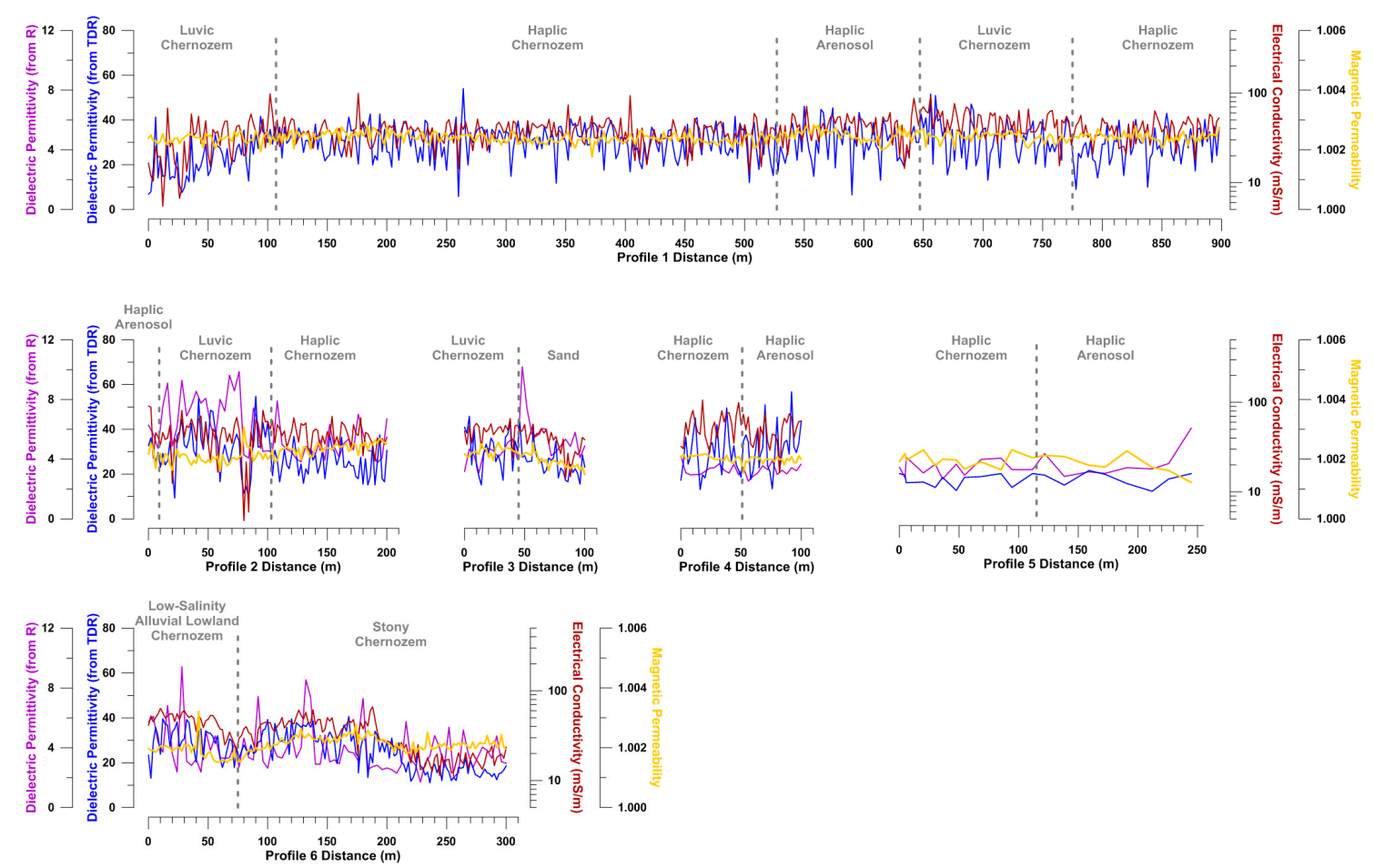

Figure 7. Field electromagnetic parameter data from six surveys transects with different lengths.

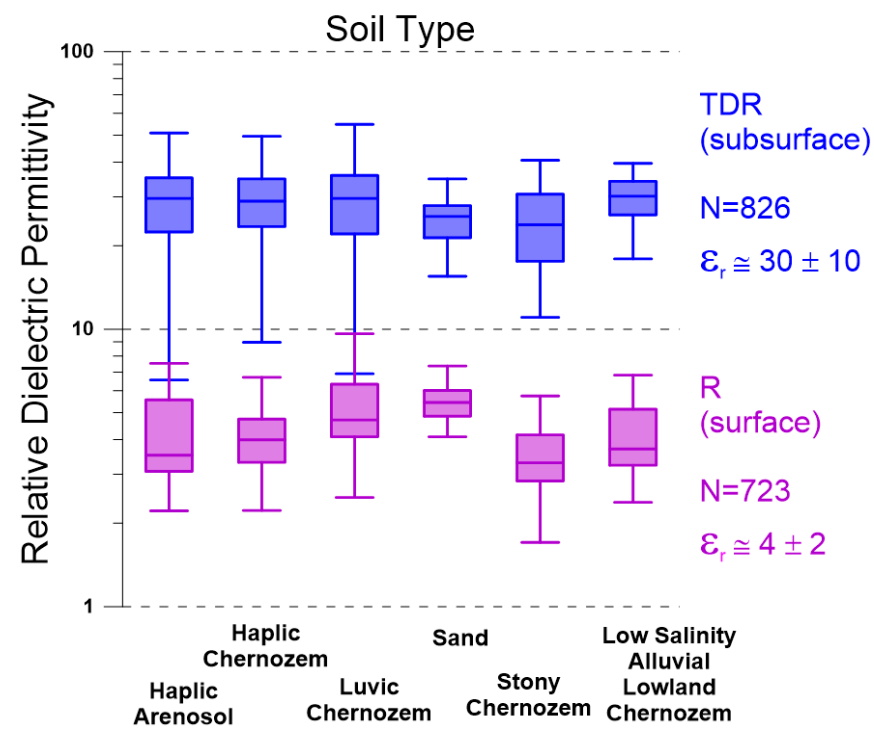

Figure 8. Comparison of the TDR- and R-based dielectric permittivities for typical Donbass soils.

In addition to the overall order of magnitude difference in the relative dielectric values for the two systems, there are local deviations that do not always track. This is readily explained by the fundamentally different methods with very different sampling footprints - a few square $\mathrm{cm}$ for TDR and $70 \times 70 \mathrm{~cm}^{2}$ for the GPR. Since these measurements were made in a recent war zone, it is also entirely 
possible that bits of shrapnel or other hardware could have influenced individual stations. However, the overall results should be accurate based on the relatively small variability of an extremely large number of measurements. No "ground truth" samples were collected for laboratory confirmation of these field values for several reasons. First, such samples would no longer represent in situ conditions so the laboratory values would differ from the field. Second, the greatest variation in field measurements will probably have resulted from contamination of the earth by anthropogenic clutter, and these variations were best represented in our large dataset covering long stretches of Donbass terrain.

The relatively higher dielectric values in the shallow subsurface may have represented an advantage since many of the Donbass mines were cased with plastics that generally had very low dielectric permittivity [41]. The high dielectric permittivity of the subsurface soils should have enhanced the GPR reflectivity of these targets.

To estimate the expected GPR velocity (V) for Donbass soils, the TDR dielectric values were converted to velocities (assuming no correction for frequency) as listed in Table 3. Note that the velocities for the various soil types were statistically indistinguishable over a huge number of measurements.

Table 3. Electromagnetic Velocities and Standard Deviation by Soil Type.

\begin{tabular}{cccc}
\hline \multirow{2}{*}{ Soil Type } & \multirow{2}{*}{ No. of Samples } & Average $\boldsymbol{v}$ & $\boldsymbol{\sigma}$ \\
\cline { 3 - 4 } & & \multicolumn{2}{c}{$(\mathbf{m} / \mathbf{n s})$} \\
\hline Haplic Arenosol & 98 & 0.058 & 0.011 \\
Haplic Chernozem & 358 & 0.058 & 0.01 \\
Luvic Chernozem & 190 & 0.059 & 0.013 \\
Sand & 28 & 0.061 & 0.007 \\
Stony Chernozem & 113 & 0.064 & 0.011 \\
Low Salinity Alluvial & 38 & 0.056 & 0.008 \\
Lowland Chernozem & & & \\
\hline
\end{tabular}

Because signal frequency is expected to have a significant effect on GPR attenuation, an attempt was made to empirically extrapolate attenuation values based on low frequency field measurements to the higher a-priori desired frequency of $2 \mathrm{GHz}$. This is depicted in Figure 9, which overlays measured values of attenuation for various earth materials at different frequency ranges. The yellow $\mathrm{X}$ symbols on Figure 9 show the field attenuations extrapolated to this frequency. At the scale of Figure 9 , the variation in attenuation values extrapolated to $1 \mathrm{GHz}$ was not evident, so they are plotted as a box and whisker on Figure 10. These values suggested that targets at $50 \mathrm{~cm}$ may have been slightly out of effective range, but the depth of typical AP mines was achievable.

During electromagnetic data collection, 26 soil samples, representing the upper $20 \mathrm{~cm}$, where collected and the weight percent moisture content determined in the laboratory by oven drying. The distribution of moisture contents is depicted by the bar graph in Figure 11. The graph also shows the variation in electromagnetic properties at $1 \mathrm{GHz}$ for chernozems with varying moisture content as abstracted from data in [43]. The effects of moisture content on many of the plotted parameters became pronounced above roughly $15 \%$ moisture, suggesting (as is commonly the case) that GPR scanning would be most effective if performed during dry seasons or periods. 


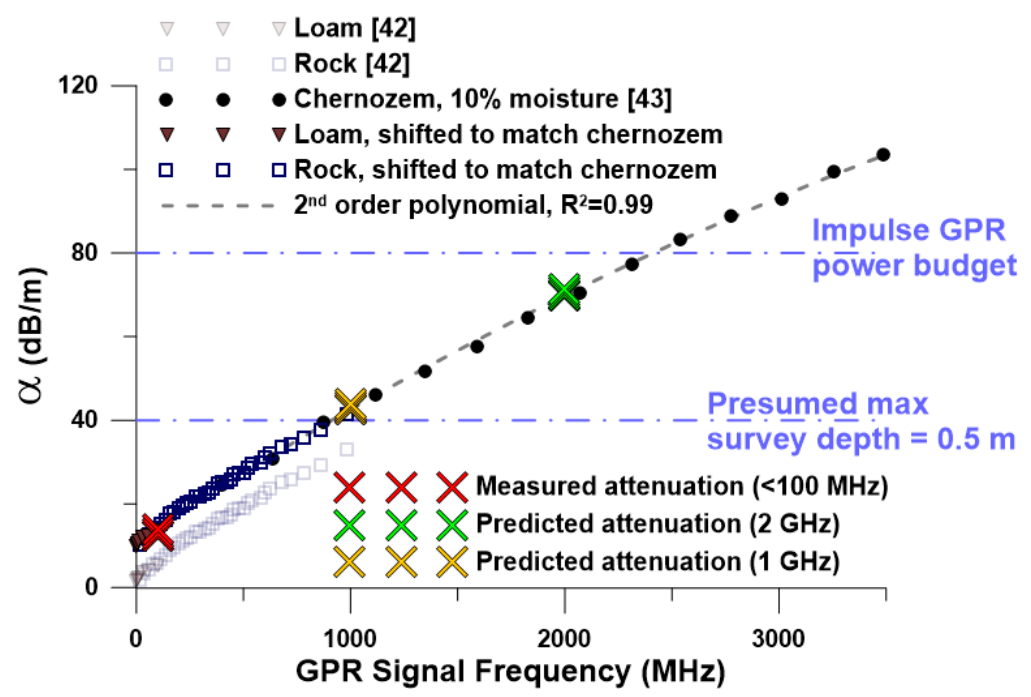

Figure 9. Empirical correction of measured attenuation based on published values $[42,43]$ for earth materials across a range of signal frequencies.

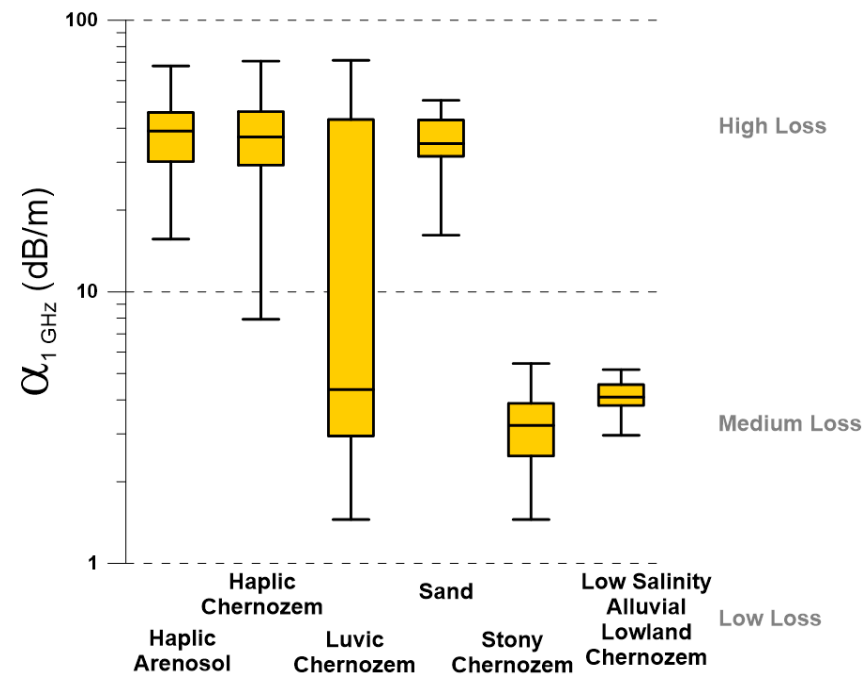

Figure 10. Estimated attenuation for a $1 \mathrm{GHz}$ signal in different local soils types.
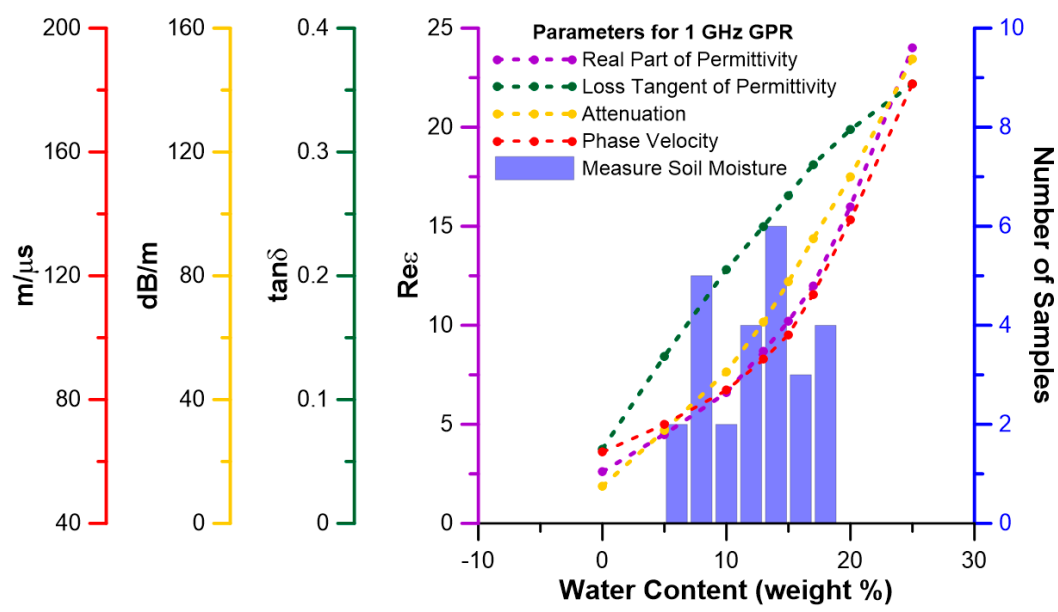

Figure 11. Measured soil moisture contents (at the time of this study) compared to variations in dielectric properties from [43]. 


\section{Conclusions}

These (first-ever) measured soil electromagnetic properties in Donbass indicate that despite the variety of mapped soils, and the huge number of measurements, the variation in electromagnetic properties is surprisingly small. Across the differing mapped soils, the estimated pulse velocities for these soils were statistically indistinguishable. They were also within the normal range for most soils worldwide and would provide time-of-flight data suitable for rapid target detection using our proposed 1-Tx and 4-Rx impulse GPR detector [35].

Soil electrical conductivity is generally high and yields crude rule-of-thumb skin depth of about $50 \mathrm{~cm}$ to $140 \mathrm{~cm}$ which is poor, but sufficient for shallow-buried AP, and maybe large metal-cased AT mines. Our measurements suggested that in the dry season, Donbass soils may develop a very dry and thin $(<$ a few $\mathrm{cm}$ ) surficial layer overlying deeper soils with mean moisture content generally between $10 \%$ and $15 \%$. This layer produced a low apparent (surficial) dielectric permittivity, with the value rising by a factor of ten across the upper $5 \mathrm{~cm}$ to $10 \mathrm{~cm}$. If this is a smooth transition, it could naturally provide a matching layer to suppress surface reflections that commonly obscure shallow subsurface targets. In addition, the relatively high dielectric beneath the surface was an advantage - providing good relative dielectric contrast for plastic-cased mines.

Estimated (extrapolated) attenuation values for $1 \mathrm{GHz}$ GPR signals in Donbass soils fell near the boundary between what was generally considered medium loss and high loss materials. For the proposed impulse GPR array currently under design \{1-Tx and 4-Rx\}, the power budget was $80 \mathrm{~dB}$. Therefore, for an expected survey depth (maximum) of $50 \mathrm{~cm}$, a COF of $1 \mathrm{GHz}$ may be preferred. At this frequency, the effective survey depth may be a bit less than $50 \mathrm{~cm}$, but this is enough for typical AP mine burial depths.

The simple combined TDR- and GPR-based determination described above, and in [35] can be readily incorporated into any humanitarian demining sensor design and/or operation. The data thus obtained can be used to increase the probability of detection for mines. For example, if soil permittivity measurements yield a value that is very close to the permittivity of expected mines, detection of such a low-contrast mines can be enhanced by (for example) denser spatial sampling, use of an increased emitted power, more averaging or signal stacking to reduce noise, and use of more bits of analog to digital conversion to allow detection of weak reflections, etc.

Measured relative magnetic permeabilities were all very close to 1 indicating no natural hindrance for MD sensors in typical Donbass chernozems.

Although these methods were applied to a particular, recently-active, war zone in Donbass, the success of this survey suggests wider applicability to other post-conflict zones for better design of landmine detector systems particularly suited to actual soil conditions rather than to those of a distant, and perhaps artificial, test bed.

Author Contributions: Conceptualization, T.B., G.P., L.C. and P.F.; data curation, A.B.; funding acquisition, T.B., G.P. and L.C.; investigation, S.T., A.S., K.V., O.O., P.K., P.F., A.B., L.B. and F.C.; methodology, V.R., L.V.-R., O.O., P.K., P.F., A.B. and L.B.; project administration, L.C., T.B. and A.B.; Software, V.R., L.V.-R. and L.B.; supervision, S.T.; validation, V.R., L.V.-R., P.K., P.F., L.B. and F.C.; visualization, A.S. and K.V.; Writing - original draft, T.B.; Writing - review and editing, S.T., G.P., L.C. and F.C.

Funding: This work was funded by the NATO Science for Peace and Security Programme, Project G5014 "Holographic and Impulse Subsurface Radar for Landmine and IED Detection" and the Franklin \& Marshall College GeoScience Founders Society and Hackman Scholars Program.

Acknowledgments: We are grateful to the brave and competent field crew at the Experimental Farm in Sukha Balka for vital field assistance.

Conflicts of Interest: The authors declare no conflict of interest.

\section{Appendix A. GPR Calibration in a Dry Sand Test Bed}

This appendix describes the calibration procedure adopted for the impulse GPR system used for the evaluation of relative permittivity. Two different approaches were used: A) time of flight (ToF) 
of reflected pulse propagation, and B) reflection coefficient. Both methods were compared with a calibration procedure in a dry sand test-bed (see Figure A1).

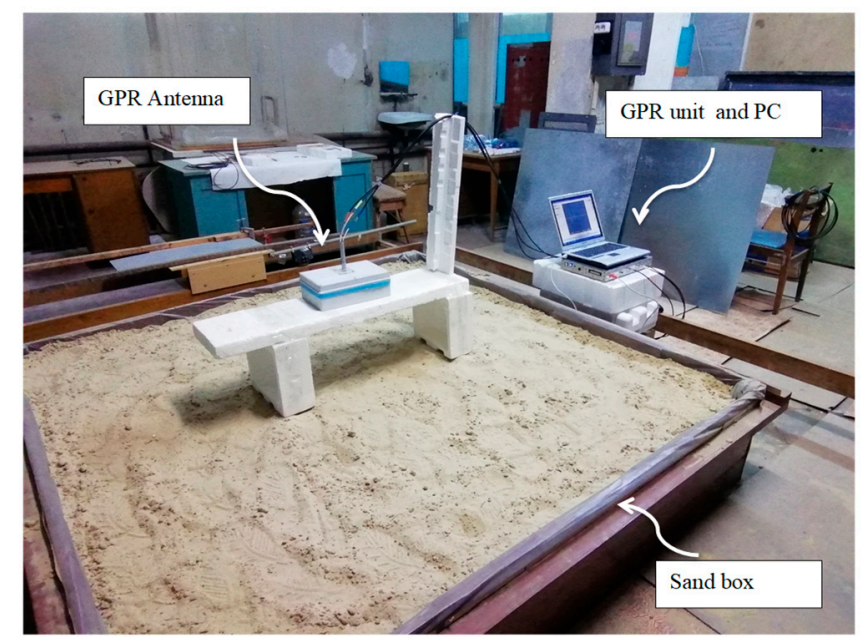

Figure A1. Laboratory sand test bed. In this photo, the antenna system rests on foam blocks above the sand surface. The control system is to the right of the test bed.

The sand box was filled four years prior to experiments, and the sand had reached the natural moisture content of the ambient laboratory air. For evaluation of the GPR impulse time of flight in sand, calibration was done using a metal sheet with dimensions $60 \mathrm{~cm} \times 38 \mathrm{~cm}$ buried at the bottom of the box (depth $\mathrm{h}=37 \mathrm{~cm}$, see Figure A2). For all measurements, the antenna system was placed above the surface of the sand at a height of $30 \mathrm{~cm}$. This allowed measurement of the ToF for the reflection from the surface of the sand. For the reflection coefficient $R$ approach, the antenna system was placed in air at distance $h=30 \mathrm{~cm}$ from the sand surface (as in Figure A1). This setup, with a metal sheet at the sand surface, was used for measurement of $R$.

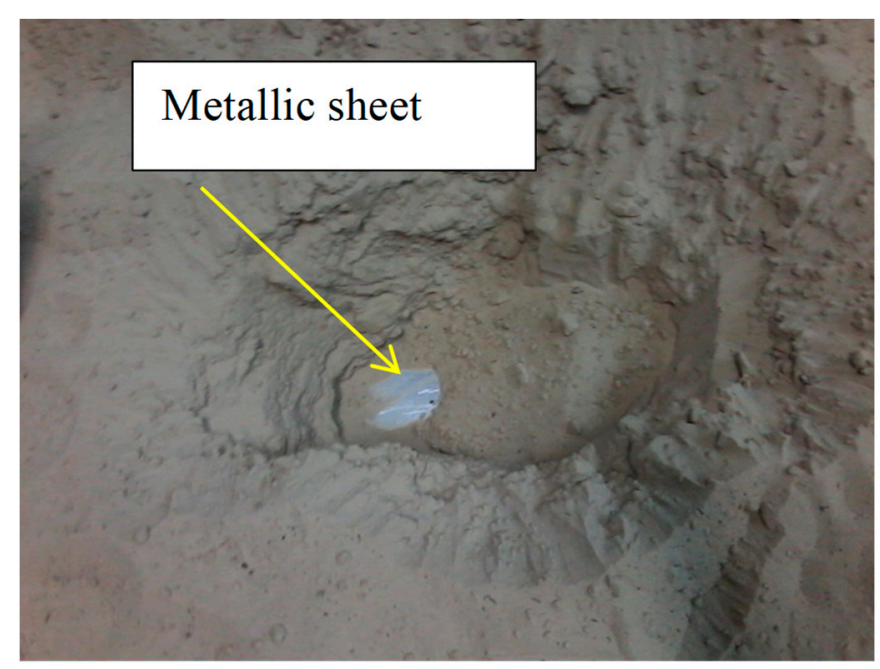

Figure A2. Metallic reflector on the bottom of the sand box.

\section{Appendix A.1. Time of Flight Method}

The plot in Figure A3, shows the reflection from the surface of the sand at time $3.58 \mathrm{~ns}$. Reflection from the buried metal sheet arrives at the receiver at time $7.61 \mathrm{~ns}$. Thus, for the signal propagating in the sand $\mathrm{ToF}=7.61 \mathrm{~ns}-3.58 \mathrm{~ns}=4.03 \mathrm{~ns}$.

$$
T o F=\frac{2 h}{v}
$$


where $v=\frac{c}{\sqrt{\varepsilon}}, c$ is speed of light, $\varepsilon$ is permittivity of sand. Replacing $v$ in (A1), we can derive $\varepsilon$ :

$$
\varepsilon=\left(\frac{c * T o F}{2 h}\right)^{2}
$$

and substituting the numerical values we obtain for the sand a reasonable value of $\varepsilon \approx 2.67$.

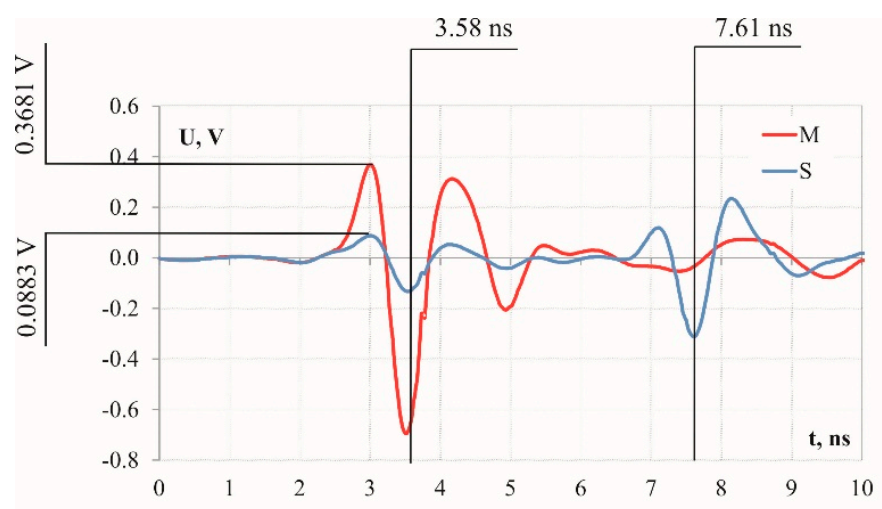

Figure A3. In the plot the two voltage signals correspond to: $\mathrm{M}$ - reflected by metallic sheet, and $\mathrm{S}$ reflected by the sand box with buried metal sheet.

\section{Appendix A.2. Reflection Coefficient Method}

The voltage amplitude of the recorded signal reflected by the surface of sand was equal to $0.0883 \mathrm{~V}$. The signal reflected from the metallic sheet lying on surface of sand had a voltage amplitude of $0.3681 \mathrm{~V}$ (see Figure A3). Thus, the reflection coefficient $\mathrm{R}$ could be calculated as:

$$
R=\frac{0.0883}{0.3681} \approx 0.24
$$

The relative permittivity of sand $\varepsilon$ is related to $\mathrm{R}$ by following formula:

$$
\varepsilon=\left(\frac{1+R}{1-R}\right)^{2}=\left(\frac{1+0.24}{1-0.24}\right)^{2} \approx 2.66
$$

Comparison of the relative permittivities obtained with the two independent approaches showed that the reflection coefficient method was in good agreement with the ToF method, and thus suitable for application in the Donbass field measurements.

\section{References}

1. UNODA. Fact Sheet; Convention on the Prohibition of the Use, Stockpiling, Production, and Transfer of Anti-Personnel Mines, and on their Destruction; UNODA: New York, NY, USA, 2016.

2. Marchenko, G. Humanitarian Demining Measures in the De-Occupied Areas of Donetsk and Luhansk Oblasts of Ukraine and Assistance to Victims of Explosive Ordnance and Military Operation of Russian Terrorist Groups; GICHD: Geneva, Switzerland, 2015.

3. MacDonald, J.; Lockwood, J.R.; McFee, J.; Altshuler, T.; Broach, T. Alternatives for landmine Detection; Rand Corp: Santa Monica, CA, USA, 2003.

4. Ivashov, S.I.; Capineri, L.; Bechtel, D.T. Holographic Subsurface Radar Technology and Applications in Ultrawideb and Radar, Applications and Design; Taylor, J.D., Ed.; CRC Press: Boca Raton, FL, USA, 2012; pp. 421-444.

5. Pochanin, G.P.; Masalov, S.A.; Ruban, V.P.; Kholod, P.V.; Batrakov, D.O.; Batrakova, A.G.; VarianytsiaRoshchupkina, L.A.; Urdzik, S.N.; Pochanin, O.G. Advances in Short-Range Distance and Permittivity Ground Penetrating Radar Measurements for Road Surface Surveying in Advanced Ultrawideband Radar, Signals, Targets, and Applications; Taylor, J.D., Ed.; CRC Press: Boca Raton, FL, USA, 2016; pp. 19-64. 
6. Borgioli, G.; Bulletti, A.; Calzolai, M.; Capineri, L. A New sensorized prodder device for the detection of vibrational characteristics of buried objects. IEEE Trans. Geosci. Remote Sens. 2014, 52, 3440-3452. [CrossRef]

7. Bechtel, T.; Capineri, L.; Windsor, C.; Inagaki, M.; Ivashov, S. Comparison of ROC Curves for Landmine Detection by Holographic Radar with ROC Data from Other Methods. In Proceedings of the 8th International Workshop on Advanced Ground Penetrating Radar (IWAGPR), Florence, Italy, 7-10 July 2015; IEEE: Piscataway, NJ, USA, 2015.

8. King, C. Demining: Enhancing the Process, in Landmines and Human Security: International Politics and War's Hidden Legacy; Matthew, R.A., McDonald, B., Rutherford, K.R., Eds.; SUNY Press: New York, NY, USA, 2004; pp. 139-149.

9. Bechtel, T.; Truskavetsky, S.; Capineri, L.; Pochanin, G.; Simic, N.; Viatkin, K.; Sherstyuk, A.; Byndych, N.; Falorni, P.; Bulletti, A.; et al. Survey of Electromagnetic Characteristics of Soils in the Donbass Region (Ukraine) for Evaluation of the Applicability of GPR and MD for Landmine Detection. In Proceedings of the 16th International Conference on Ground Penetrating Radar (GPR), Hong Kong, China, 13-16 June 2016; pp. 1-6, IWAGPR.

10. Pochanin, G.P.; Kholod, P.; Glazounov, V.; Efimova, N. New Lines of Approach to the Problem of Plastic Mines Detection by GPR Method. In Proceedings of the European Association of Geoscientists \& Engineers 63rd Conference and Technical Exhibition, Amsterdam, Houten, The Netherlands, 11-15 June 2001; pp. 143-148.

11. Miller, T.W.; Borchers, B.; Hendrickx, J.M.H.; Hong, S.; Dekker, L.W.; Ritsema, C.J. Effects of Soil Physical Properties on GPR for Landmine Detection. In Proceedings of the Fifth International Symposium on Technology and the Mine Problem, Monterey, CA, USA, 22-26 April 2002.

12. Riahi, M.; Tavangar, A. Prediction of GPR Performance in Landmine Detection. In Proceedings of SPIE, Nondestructive Characterization for Composite Materials, Aerospace Engineering, Civil Infrastructure, and Homeland Security; SPIE: Bellingham, WA, USA, 2009; Volume 7294.

13. Borchers, B.J.; Hendrickx, J.M.H.; Das, B.S.; Hong, S. Enhancing Dielectric Contrast Between Land Mines and the Soil Environment by Watering: Modeling, Design, and Experimental Results. In Proceedings of SPIE; SPIE: Bellingham, WA, USA, 2000; Volume 4038, pp. 993-1000.

14. Igel, J.; Preetz, H. Small-Scale Variability of Electromagnetic Soil Properties and Their Influence on Landmine Detection: How to Measure, How to Analyze, and How to Interpret? In Proceedings of SPIE, Detection and Sensing of Mines, Explosive Objects, and Obscured Targets XIV, 730312; SPIE: Bellingham, WA, USA, 2009; Volume 7303.

15. Petrenko, V.D.; Kovalevych, V.V. The Results of the Defect Places Investigation of Donetsk Railway Road Bed by Ground Penetrating Radar Complex. Science and Progress in Transport. Bull. Dnepropetr. Natl. Univ. Railw. Trans. 2014, 5. [CrossRef]

16. Sugak VGBukin, A.V.; Reznichenko, N.G.; Djadoo, A. Forward Looking Ground Penetrating Radar with Synthetic Antenna Aperture for Buried Explosive Hazards Detection. In Proceedings of the 9th International Kharkiv Symposium on Physics and Engineering of Microwaves, Millimeter and Submillimeter Waves (MSMW), Kharkiv, Ukraine, 20-24 June 2016; IEEE: Piscataway, NJ, USA, 2016.

17. Koshovyy, V.; Alokhina, O.; Skierucha, W.; Wilczek, A.; Pastuszka, T.; Cymerman, J. Peculiarities of soil moisture and temperature dynamics based on TDR-measurement results for 2008-2012 in the western Polesie territory of Ukraine Acta Agrophysica. Acta Agrophys. 2013, 20, 577-593.

18. Food and Agriculture Organization. Digital Soil Map of the World; World Soil Resources Report; FAO: Rome, Italy, 2009.

19. Yarovenko, F. Soils of Donetsk Region, Donetsk: "Donbass"; Kharkov Agricultural Institute: Kharkov, Ukrainian SSR, 1969; 56p. (In Ukranian)

20. Krupsky, N.K.; Polupan, N.I. Atlas of soils of the Ukrainian SSR, Kiev: "Harvest"; Urozhai: Kyiv, Ukrainian SSR, 1979; 160p. (In Russian)

21. Medvedev, V.V.; Laktionova, T.M.; Kanash, O.P. Soils of the Ukraine (Genesis and Agronomical Characteristics); University Publishing House: Kharkiv, Ukraine, 2003; 68p. (In Ukranian)

22. Daniels, D.J. Ground Penetrating Radar for Buried Landmine and IED Detection. In Unexploded Ordnance Detection and Mitigation; NATO Science for Peace and Security Series B: Physics and Biophysics; Byrnes, J., Ed.; Springer: Dordrecht, The Netherlands, 2009; pp. 89-111.

23. Comité Européen De Normalisation (Europäisches Komitee Für Normung). Humanitarian Mine Action-Test and Evaluation-Part 1: Metal Detectors; De Normalisation, Comité Européen, and Europäisches Komitee Für Normung: Brussels, Belgium, 2003. 
24. Takahashi, K.; Holger, P.; Igel, J. Soil properties and performance of landmine detection by metal detector and ground-penetrating radar-Soil characterisation and its verification by a field test. J. Appl. Geophys. 2011, 73, 368-377. [CrossRef]

25. Finkelshtain, M.I.; Karpukhin, V.I.; Kutev, V.A.; Metelkin, V.N. Subsurface Radiolocation; Radio I Sviaz: Moscow, Russia, 1994; p. 216.

26. Lecoanet, H.; Lévêque, F.; Segura, S. Magnetic Susceptibility in Environmental Applications: Comparison of Field Probes. Phys. Earth Planet. Inter. 1999, 115, 191-204. [CrossRef]

27. Samouëlian, A.; Isabelle, C.; Alain, T.; Bruand, A.; Guy, R. Electrical resistivity survey in soil science: A review. Soil Tillage Res. 2005, 83, 173-193. [CrossRef]

28. Robinson, D.A.; Jones, S.B.; Wraith, J.M.; Or, D.; Friedman, S.P. A review of advances in dielectric and electrical conductivity measurement in soils using time domain reflectometry. Vadose Zone J. 2003, 2, 444-475. [CrossRef]

29. AMaryott, A.; Smith, E.R. Table of Dielectric Constants of Pure Liquids; No. NBS-514; National Bureau of Standards: Gaithersburg, MD, USA, 1951.

30. Epp, L.W.; Mittra, R.; McCormack, R.G. Summary of Methods for Measuring Electrical Properties of Geological Strata to Estimate Electromagnetic Shielding Effectiveness; Construction Engineering Research Laboratory: Champaign, IL, USA; National Technical Information Service: Springfield, VA, USA, 1988.

31. Capineri, L.; Daniels, D.J.; Falorni, P.; Lopera, O.L.; Windsor, C.G. Estimation of relative permittivity of shallow soils by using the ground penetrating radar response from different buried targets. Prog. Electromagn. Res. Lett. 2008, 2, 63-71. [CrossRef]

32. Golovko, M.M.; Pochanin, G.P. Automatic Measurement of Ground Permittivity and Automatic Detection of Object Location with GPR Images Containing a Response from A Local Object in Ultrawideband Radar Applications and Design; Taylor, J.D., Ed.; CRC Press: Boca Raton, FL, USA, 2012; pp. 231-251.

33. Jol, H.M. Ground Penetrating Radar: Theory and Applications; Elsevier Science: Amsterdam, The Netherlands, 2009.

34. Igel, J. The small-Scale Variability of Electrical Soil Properties-Influence on GPR Measurements. In Proceedings of the 12th International Conference on Ground Penetrating Radar, Birmingham, UK, 16-19 June 2008.

35. Pochanin, G.; Varianytsia-Roshchupkina, L.; Ruban, V.; Pochanina, I.; Falorni, P.; Borgioli, G.; Capineri, L.; Bechtel, T. Design and Simulation of a Single Transmitter-Four Receiver Impulse GPR for Detection of Buried Landmines. In Proceedings of the 9th International Workshop on Advanced Ground Penetrating Radar (IWAGPR), Edinburgh, UK, 28-30 June 2017; pp. 1-5.

36. Soldovieri, F.; Prisco, G.; Persico, R.; Golovko, M.; Pochanin, G. Two Strategies for the Determination of Soil Permittivity by GPR Data. In Proceedings of the 12th International Conference on Ground Penetrating Radar University of Birmingham, Birmingham, UK, 15-19 June 2008.

37. Lambot, S.; Slob, E.C.; van den Bosch, I.; Stockbroeckx, B.; Scheers, B.; Vanclooster, M. Estimating soil electric properties from monostatic ground-penetrating radar signal inversion in the frequency domain. Water Resour. Res. 2004, 40. [CrossRef]

38. Kopylov, Y.A.; Masalov, S.A.; Pochanin, G.P. Method for Decoupling Between Transmitting and Receiving Modules of Antenna System. U.A. Patent 81652, 25 January 2008.

39. LVarianytsia-Roshchupkina; Pochanin, G.P.; Pochanina, I.Y.; Masalov, S.A. Comparison of Different Antenna Configurations for Probing of Layered Media. In Proceedings of the 8th International Workshop on Advanced Ground Penetrating Radar, Florence, Italy, 7-10 July 2015; IEEE: Piscataway, NJ, USA, 2015.

40. Herz, N.; Garrison, E.G. Geological Methods for Archaeology; Oxford University Press: Oxford, UK, 1997.

41. Hari, S.N. (Ed.) Handbook of low and High Dielectric Constant Materials and Their Applications; Two-Volume Set; Academic Press: Cambridge, MA, USA, 1999.

42. Turner, G.; Anthony, F.S. Constant Q Attenuation of Subsurface Radar Pulses. Geophysics 1994, 59, $1192-1200$. [CrossRef]

43. Filonenko, V.A.; Chubinsky, N.P. Measuring the electric parameters of chernozem with various moisture contents in the frequency range 250-3500 MHz. J. Commun. Technol. Electron. 2006, 51, 685-690. [CrossRef]

(C) 2019 by the authors. Licensee MDPI, Basel, Switzerland. This article is an open access article distributed under the terms and conditions of the Creative Commons Attribution (CC BY) license (http://creativecommons.org/licenses/by/4.0/). 